\title{
Application of Glisson Pedicle Transection Hepatectomy in the Anatomic Hepatic Resection
}

\author{
B-Q Wu, Y Jiang*', F Zhu, D-L Sun
}

\begin{abstract}
Objective: This study aims to investigate the application of Glisson pedicle transection hepatectomy in the anatomic hepatic resection.

Methods: Forty-five patients with hepatocellular carcinoma (HCC) were treated by liver resection using Glisson pedicle transection hepatectomy by the same surgical group during June, 2009 and June, 2012 and their clinical data during the peri-operative period were retrospectively analysed. Follow-up was performed for one-year.

Results: In the selected 45 cases, $82.2 \%$ (37/45) of the patients underwent anatomical hepatectomy. Bile leakage and bleeding occurred in six cases during the belting of the three main hepatic pedicles, which were treated by local compression or proper stitching. The recurrence rate one-year after surgery was $15.6 \%(7 / 45)$ and the survival rate was $80.0 \%(36 / 45)$ in one-year.

Conclusion: Glisson pedicle transection hepatectomy had advantages of embodying regional hepatichilus blocking and avoiding the cumbersome anatomy of hepatichilus vessels. It is also consistent with the principles of radical cure for tumours and precise liver resection.
\end{abstract}

Keywords: Anatomic liver resection, Glisson pedicle transaction, primary liver cancer

\section{Aplicación de la Hepatectomía Mediante Transección del Pedículo de Glisson en la Resección Hepática Anatómica}

B-Q Wu, Y Jiang*, F Zhu, D-L Sun

\begin{abstract}
RESUMEN
Objetivo: Este estudio está encaminado a investigar la aplicación de la hepatectomía mediante transección del pedículo de Glisson en la resección hepática anatómica

Métodos: Cuarenta y cinco pacientes con carcinoma hepatocelular (HCC) fueron tratados mediante resección hepática usando hepatectomía mediante transección del pedículo glissoniano por el mismo grupo quirúrgico durante junio de 2009 y junio de 2012, y sus datos clínicos durante el periodo peri-operatorio fueron analizados retrospectivamente. Se realizó un seguimiento de un año.

Resultados: De los 45 casos seleccionados, 82.2\% (37/45) de los pacientes experimentó hepatectomía anatómica. En seis casos se produjo escape de bilis y sangramiento durante el pinzamiento de los tres pedículos principales. Tanto el escape de bilis como el sangramiento fueron tratados mediante compresión local o sutura adecuada. La tasa de recurrencia un año después de la cirugía fue de 15.6\% (7/45) y la tasa de supervivencia fue de $80.0 \%$ (36/45) en un año.

Conclusión: La hepatectomía mediante transección del pedículo glissoniano tuvo como ventajas incorporar el bloqueo de la región del hilio hepático y evitar la complicada anatomía de los vasos del hilio hepático. También concuerda con los principios de la cura radical de tumores y la resección hepática precisa.
\end{abstract}

Palabras claves: resección anatómica del hígado, transección del pedículo glissoniano, cáncer primario del hígado

West Indian Med J 2017; 66 (1): 31

From: Department of Hepatatobiliary Surgery, the Third Affiliated Hospital of Suzhou University, Changzhou 213003, Jiangsu Province, China.
Correspondence: Dr Y Jiang, Department of Hepatatobiliary Surgery, The Third Affiliated Hospital of Suzhou University, Changzhou 213003, Jiangsu Province, China. Fax: +86-0519-86621235, e-mail: yongjiangcn@126.com 


\section{INTRODUCTION}

Primary liver cancer, is the fifth common cancer and the third cause of tumour-associated leading deaths in the world (1). The number of new liver cancers in China accounted for about $55 \%$ each year in the whole world, the incidence rate exceeds 50/100 000; hepatocellular carcinoma (HCC) is the second most prevalent tumour impacting people's health (2). The treatment for liver cancers include surgical resection, liver transplantation, intervention, radiofrequency ablation and other auxiliary therapies, but resection is still the most effective and preferred means to treat liver cancers currently (3).

The liver resection for liver cancer could be divided into anatomical liver resection and non-anatomic liver resection. It has been shown that (4) the small branches of the portal vein were tumour-closed blood vessels with intrahepatic metastasis via the portal venous system, which was a major site for dissemination of primary liver cancer. Therefore, the anatomic hepatic resection with the range of liver segments and lobes of liver conforms to the anatomy and physiology of the liver because it resects the portal veins and its branches over the liver tumours, which provide the tumour distribution region, could significantly improve the prognosis of patients after the cancer surgery $(5,6)$.

Conventional anatomic liver resection selected the first hepatic portal, blocked, ligated and cut off the required arteries in the lobes of liver and portal veins according to the selected range for liver resection, then resected the liver in light of the ischaemia boundaries or marking lines on the liver surface. "Glisson pedicle transection hepatectomy" was first reported by professor Takasaki in 1986 (7). The theoretical basis of the method was the known "portal triad" of the hepatic artery, portal vein and bile ducts surrounded by connective tissues of the Glisson sheaths which formed three coarse Glisson sheaths in the hilus hepatis and stretched into the hepatic portals, and dominated the left hepatic lobes, the right anterior lobes of the liver and the right posterior lobes respectively, so they were able to be separated entirely according to the anatomy walk marks of the three hepatic pedicles.

Ischaemic tag lines occurs in the left liver, the anterior right liver and the posterior right liver on the liver surface after tightening the blockades. The corresponding lobes of liver and liver segments were resected along the liver ischaemic lines. This method was relatively simple to operate. It can shorten the time of hilar dissection and avoid the possible injuries to hilar bile ducts and vasculature generated in the separate vascular anatomy, blocking or ligating the portal veins bearing cancers before the liver tissue resection were the key to prevent intrahepatic metastasis of tumour during surgery $(8,9)$. The author performed HCC liver resection in 45 cases using the "Glisson pedicle transection hepatectomy" during June, 2009 and June, 2012 including 37 cases of anatomical liver resection (accounting for $82.2 \%$ ). The results are reported as follows.

\section{SUBJECTS AND METHODS General data}

Forty-five cases with HCC liver resection using Glisson pedicle transection hepatectomy, admitted to the Third Affiliated Hospital of Suzhou University during June, 2009 and June, 2012, were retrospective analysed. They included 37 cases with anatomical liver resection. The relevant information of the 45 patients were as follows: 31 males and 14 females, aged 24 to 76 years with mean age of 47.2 years old; 40 cases had various degrees of hepatocirrhosis, 39 cases with tumour number $\leq 2$ and six cases with tumour number $\leq 3,38$ cases with grade $\mathrm{A}$ and 7 cases with grade $\mathrm{B}$ according to the Child-Pugh grading of liver function, tumour size was $2.5 \sim 14.0 \mathrm{~cm}$ with an average of $7.5 \mathrm{~cm}$. This study was conducted in accordance with the Declaration of Helsinki. This study was conducted with approval from the Ethics Committee of the Third Affiliated Hospital of Suzhou University. Written informed consent was obtained from all participants.

\section{Surgical methods}

All patients were supine and received general anaesthesia via tracheal intubation, invasion was made in the right subcostal anti-L shaped or bilateral subcostal inverted T-shaped conventionally, the abdominal cavity was examined to determine if the liver tumours could be resected, and then the ligaments around the liver were fully freed.

According to the "three sections dissection of liver" theory described by Takasaki (Fig. 1):

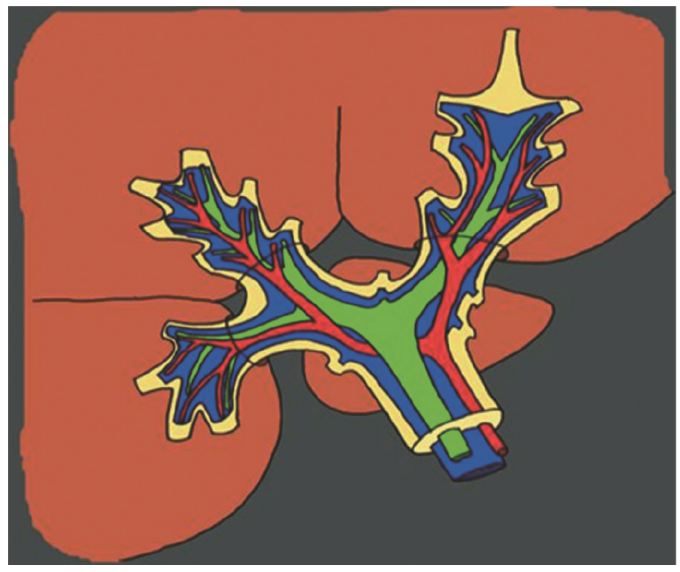

Fig. 1: The liver is divided into three segments according to the ramification of the Glissonean pedicles.

the hepatic artery, portal vein, bile ducts, (portal triad), surrounded by connective tissue of the Glisson sheath in the liver, formed three coarse Glisson sheath in the hilar hepatis and stretched into the liver, that is the left hepatic segment (left branches), the liver segment (right anterior branches), the hepatic segment (right posterior branches) respectively, so the "portal triad" needed to be dissected separately, but separated as a whole according to the path of the Glisson sheath outside the hepatic pedicles. 
The midline of the gallbladder was taken as the anatomical mark of the middle segment (the anterior right lobes) for hepatic pedicles, drew a perpendicular line to midline intersected in the gallbladder neck as the anatomical mark of right hepatic segment (the posterior right lobes) for hepatic pedicles, and took toward liver segment of round ligament of liver to nearly liver side as the anatomical marks of the left hepatic segment (the left lobes).

In surgery, cholecystectomy was first performed generally by removed connective tissues on the gallbladder board, bluntly separated the peritoneum in the junction of the liver capsule and the gallbladder plate using tangential clamps from the left and the right, bluntly peeled the liver parenchyma and Glisson sheath and sucked the small bleeding by using a suction apparatus. Separated the left edge and the right edge of the right front Glisson pedicle around the back by the rightangle clamp after clearly exposing, and suspended with a fine catheter. Using the same method to treat the right after Glisson pedicles. Sometimes, it was difficult to separate the right posterior branches alone, so it could adopt suspend the entire right lobe Glisson pedicles, and then rounded the blocking from the back of the right anterior branches (Fig. 2), thus, it was easy to operate the separation of the right posterior branches, and could free the liver pedicles of the left lobes by taking the ligamenta teres hepatis as boundary, and the bandages of three major sets of hepatic pedicles were completed (Fig. 3), clear boundaries of half liver and among liver lobes could be visible when the blocking belts were tightened.

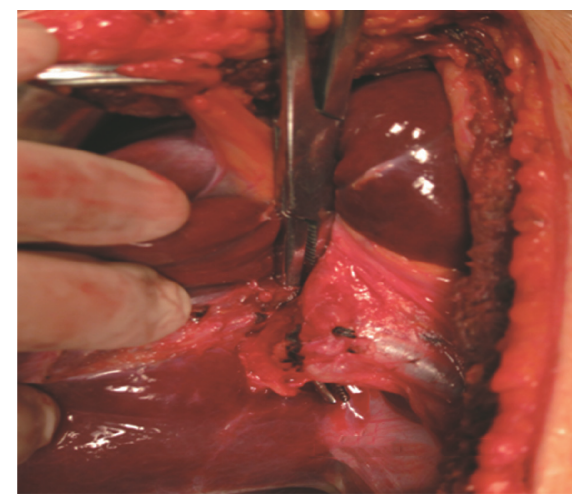

Fig. 2: The right pedicle can be approached at the right end of the hilar plate.

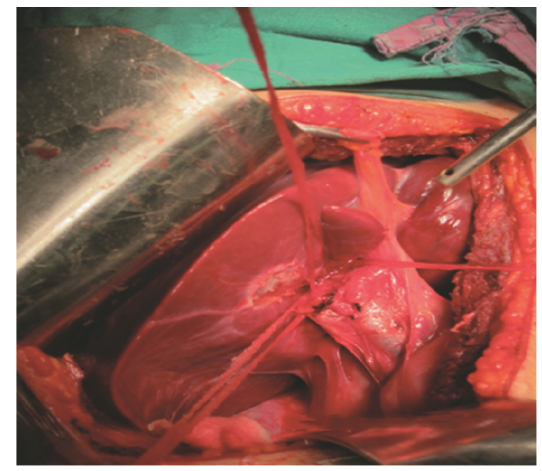

Fig. 3: The left hepatic pedicle, right anterior and posterior sectional pedicle were isolated and suspended.

\section{Observed indicators and follow-ups}

All the operative time, blood loss, blood transfusion, preoperative and postoperative liver function, postoperative major complications (including bleeding, biliary fistula, hepatic dysfunction, pleural effusion and subphrenic infection etc), operative mortality, hospital duration of the patients were recorded. The contents of follow-ups: all patients were re-examined as outpatients by liver B-mode ultrasonography every three months. Further enhanced computed tomography or magnetic resonance imaging were performed if tumour recurrence was suspected or alpha fetoprotein was increasing in the B-mode ultrasonography.

\section{RESULTS}

\section{Hepatectomy methods}

The anatomical hepatectomy patients accounted for $82.2 \%$ (37/45) in the 45 cases, including five cases using right posterior lobe resection (VI + VII segment), four cases using the right anterior lobe resection $(\mathrm{V}+\mathrm{VIII})$, six cases using right hepatectomy (V + VIII + VI + VII segment), 10 cases using left lateral lobe resection (II + III segment), six cases using left half liver resection (II + III + IV segment) and six cases using other forms of anatomical resection. Another eight cases were performed by non-anatomic liver resection such as partial liver resection and excavation.

\section{Surgical findings, surgical complications and postopera- tive follow-ups for one year}

There was no surgical and hospital deaths in the 45 patients, six cases had bile leakage and bleeding into the bandages of the three main hepatic pedicles, and were all treated by local compression or proper stitching. The mean operative time was 172 \pm 78 minutes, surgery bleeding volume was $550 \pm 350 \mathrm{~mL}$, intra-operative blood transfusion was $450 \pm 250 \mathrm{Ml}$. Two cases had postoperative bile leakage, two cases had re-bleeding including one case that underwent secondary surgery to stop bleeding, and the others were managed successfully by conservative treatment. The alanine aminotransferase was 278.8 $\pm 54.5 \mathrm{umol} / \mathrm{L}$ two days after surgery, and 76.9 $\pm 45.2 \mathrm{umol} / \mathrm{L}$ a week after surgery. Three cases had postoperative hepatic dysfunction with clinical performances of massive ascites, deepening jaundice or encephalopathy that improved after proper treatment. The postoperative recurrence rate of tumours was $15.6 \%$ in one year $(7 / 45)$, and the postoperative survival rate was $80.0 \%$ in one year $(36 / 45)$.

\section{DISCUSSION}

There are two ways to perform radical surgical resection in the liner (10): anatomical and non-anatomical liver resection. The anatomical liver resection takes the liver as the basic unit of hepatic resection, resected the liver tissues with ranges of surgical anatomy: the liver segment, lobes of liver, half liver or liver clover. The non-anatomic resection is irregular resection such as local tumour excision, and wedge resection a certain distance from the tumour margins. The current studies (4) 
considered that the primary liver cancer was transferred via the portal veins and the portal vein branches. Thus, according to the mechanism of the early HCC tumour, micro-metastases were in the same liver segment with the main tumours; thus anatomical liver resection in could help to improve the prognosis of patients with $\mathrm{HCC}$ liver resection in theory, which was considered to be the ideal method of liver resection for liver cancers $(5,6)$.

Generally, two ways were available for separating structures of hepatic hilus by anatomical liver resection: the first one was dissecting the intrathecal structures and block them one by one. The second one was dealing with the intrathecal structures Glisson sheaths as a whole. The former operation was relatively cumbersome and may damage the vascular sheath, and it was difficulty to dissect the secondary pipelines of the hilus hepatis with all its variations. And the latter took the Glisson sheaths as a unit, dealt with the hepatic arteries, the portal veins and the bile ducts at the same time; based on the path of hilar hepatic pedicles, it was relatively simple to operate, and could shorten the time of hilus hepatis anatomy and avoid the bile duct injuries of the hilus hepatis segment and vascular injuries that may arise in the respective vascular anatomy. The portal vein blocking or ligation of tumour bearing vessels before liver tissue mutilation were the key to prevent intrahepatic metastasis of tumours in the surgery.

The "Glisson pedicle transection hepatectomy", first reported by Professor Takasaki in 1986 (7), was ideal to deal with structures of hilus hepatis segments as a whole. The theoretical method is the known "portal triad" of the hepatic artery, portal vein and bile ducts surrounded by connective tissue of Glisson and stretched into the hepatic portal, dominated the left hepatic lobes, the right anterior lobes of liver and the right posterior lobes of liver, thus, they could be treated as a whole according to the anatomical paths for the three hepatic pedicles, sharp ischaemic tag lines of the left liver, the right anterior lobes of liver and the right posterior lobes of the liver were visible on the liver surface when the blockades were tightened, and it was therefore possible to perform corresponding resection of the lobes of liver and liver segments along the liver ischaemic bands.

The traditional Pringle Pringle's method of hilus hepatis blocking was non-selective hepatic inflow occlusion (11), there were no obvious ischaemic liver surface boundaries, the surgeon could only perform hepatectomy in accordance with the anatomical tag lines on the surface of the liver, the guide was poor, or only non-anatomic liver resection could be carried out, and the blood supply of the normal liver tissue was blocked at the same time, resulting in the contralateral hepatic ischaemiareperfusion injury, which undoubtedly increased the risk of postoperative liver failure in a patient with liver cancer combined with cirrhosis (12). Ji et al (13) compared the Glisson pedicle transection hilus hepatis blocking and the traditional Pringle's method, finding that the former was significantly superior to the latter in aspects of hilus hepatis blocking time, blood loss, blood transfusion and disappearance of postoperative ascites $(p<0.01)$. The studies of Chen (14) showed that "Glisson pedicle transection hepatectomy" had a lower positive rate for resected margins and postoperative recurrence rate in one year than that of the conventional liver resection. The anatomical liver resection in this study group reached up to $82.2 \%$, the postoperative recurrence rate was $15.6 \%$ in one year, and the survival rate reached up to $80.0 \%$ one year after surgery.

The large randomized study of Figueras (8) showed the "Glisson pedicle transection hepatectomy" with faster postoperative recovery of liver enzymes, block of the hilus hepatis more quickly and effectively compared with the semihepatic occlusion commonly used in clinical anatomy $(p<0.05)$. Therefore, compared with the traditional Pringle's method for controlling all hepatic blood flow, the advantages of Glisson pedicle transection hepatectomy not only reflected local control of blood flow to protect residual liver function, but also the ideal method of achieving anatomical liver resection to prevent liver tumour metastatic $(8,9)$. Compared with the respective dissection of vessels in the hilus hepatis segments, the operation of the Glisson pedicle transection hepatectomy was relatively simple, and can shorten the time of hilus hepatis anatomy and avoid bile duct injuries in the hilus hepatis segments and vascular injuries when respective dissection was performed (15).

Currently, the technique of blocking the hepatic blood flow via Glisson sheath paths is not only respected by many hepatic surgeons, but also laparoscopic is widely use in the resection (16-18). Of course, the successful bandages of the Glisson pedicle need experience (19), and the method could not be used when liver cancer combined with hilar vascular bolt in the hilus hepatis segments or in major variations of pipelines existed; it should be replaced by the anatomical hilar vascular occlusion technique proposed by Makuuchi (20). We also gradually gained some surgical techniques in practice: (a) blocked can be temporarily performed under the Pringle's method to have favourable vision not obscured by bleeding when binding; (b) one should be careful to check for any resistance when using the curved forceps to draw out the back of the hepatic pedicles, using the fingers to feel the tissues between the pliers; and (c) the forceps should act between the liver parenchyma and Glisson pedicles, it could not accurately judge the gap if the forceps were too close to the Glisson pedicles due to the tenacious sheaths, while blurry vision appeared caused by bleeding if the forceps were too close to liver parenchyma, so the surrounding of the Glisson sheath must be fully freed to reveal the gap with the liver parenchyma.

We believed that Glisson pedicle transection hepatectomy was a better way to perform liver resection oriented to liver segments. The advantages were not only reflected in faster regional hilus hepatis blockage and avoiding the cumbersome dessecting of the vessels in the hilus hepatis segments, but also complied with tumour cure principles and embodied precise hepatectomy. 


\section{AUTHORS' NOTE}

The authors declare that they have no conflict of interest.

\section{REFERENCES}

1. Fares N, Péron JM. Epidemiology, natural history, and risk factors of hepatocellular carcinoma. Rev Prat 2013; 63: 216-7, 220-2.

2. Bosch FX, Ribes J, Cléries R, Díaz M. Epidemiology of hepatocellular carcinoma. Clin Liver Dis 2005; 9: 191-211. doi:10.1016/j.cld. 2004.12.009

3. Forner A, Llovet JM, Bruix J. Hepatocellular carcinoma. Lancet 2012; 379: 1245-55. doi: 10.1016/S0140-6736(11)61347-0.

4. Toyosaka A, Okamoto E, Mitsunobu M, Oriyama T, Nakao N, Miura K. Intrahepatic metastases in hepatocellular carcinoma: evidence for spread via the portal vein as an efferent vessel. Am J Gastroenterol 1996; 91: 1610-5.

5. Agrawal S, Belghiti J. Oncologic resection for malignant tumors of the liver. Ann Surg 2011; 253: 656-65. doi: 10.1097/SLA.0b013e3181fc08ca.

6. Ochiai T, Ikoma H, Yamamoto Y, Konishi H, Murayama Y, Shiozaki A et al. Anatomical hepatectomy for hepatocellular carcinoma in patients with preserved liver function. Anticancer Res 2013; 33: 1689-95.

7. Takasaki K. Glissonean pedicle transection method for hepatic resection: a new concept of liver segmentation. J Hepatobiliary Pancreat Surg 1998; 5: 286-91.

8. Figueras J, Lopez-Ben S, Lladó L, Rafecas A, Torras J, Ramos E et al. Hilar Dissection versus the "Gissonean" approach and Stapling of the Pedicle for Major Hepatectomies: A Prospective, Randomized Trial. Ann Surg 2003; 238: 111-9. doi: 10.1097/01.SLA.0000074981.02000.69

9. Yamamoto M, Katagiri S, Ariizumi S, Kotera Y, Takahashi Y. Glissonean pedicle transection method for liver surgery. J Hepatobiliary Pancreat Sci 2012; 19: 3-8. doi: 10.1007/s00534-011-0443-0.

10. Ye JF, Wu FX, Zhao YN, Li LQ, You XM. Recurrence after anatomic versus nonanatomic resection for hepatocellular carc inoma: a Metaanalysis. Chin J Hepatobiliary 2012; 18: 582-8. DOI: 10.3760/cma.j. issn.1007-8118.2012.08.004

11. van Gulik TM, de Graaf W, Dinant S, Busch OR, Gouma DJ. Vascular occlusion techniques during liver resection. Dig Surg 2007; 24: 274-81. DOI:10.1159/000103658

12. Hoekstra LT, van Trigt JD, Reiniers MJ, Busch OR, Gouma DJ, van Gulik TM. Vascular occlusion or not during liver resection: the continuing story. Dig Surg 2012; 29: 35-42. doi: 10.1159/000335724.

13. Ji B, Wang Y, Wang G, Liu Y. Curative resection of hepatocellular carcinoma using modified Glissonean pedicle transection versus the Pringle maneuver: a case control study. Int J Med Sci 2012; 9: 843-52. doi: 10.7150/ijms.4870.

14. Chen XP, Ou DP, Chen SH, Sun ND, Shi ZS, Wang Z. Segmental resection of the liver by Glissonean pedicle transection for primary liver cancer. Nan Fang Yi Ke Da Xue Xue Bao 2010; 30: 362-3.

15. Karamarković A, Doklestić K, Milić N, Djukić V, Bumbasirević V, Sijački A et al. Glissonean pedicle approach in major liver resections. Hepatogastroenterology. 2012; 59: 1896-901. doi: 10.5754/hge12198.

16. Cho A, Yamamoto H, Kainuma O, Ota T, Park S, Yanagibashi H et al. Arantius' ligament approach for the left extrahepatic Glissonean pedicle in pure laparoscopic left hemihepatectomy. Asian J Endosc Surg 2012; 5: 187-90. doi: 10.1111/j.1758-5910.2012.00139.x.

17. Lv SC, Shi XJ, Wang HG, Ji WB, Liang YR, Luo Y et al. An exploration to the standard operation plan of Laparoscopic hepatic left lateral lobectomy. Chin J Laparoscopic surgery (Electronic Edition) 2011; 4: 15-8. doi: 10.3877/cma.j.issn.1674-6899.2011.02.005

18. Rotellar F, Pardo F, Benito A, Martí-Cruchaga P, Zozaya G, Pedano N. A novel extra-glissonian approach for totally laparoscopic left hepatectomy. Surg Endosc 2012; 26: 2617-22. doi: 10.1007/s00464-012-2242-3.

19. Tang JH, Fu BM, Tang B, Li HY, Zhu H, Zhang J. The operation curve of anatomic hepatectomy with Glissonean pedicle transection method for hepatic resection. Journal of Kunming Medical University 2010; 31: 2933.

20. Makuuchi M, Mori T, Gunvén P, Yamazaki S, Hasegawa H. Safety of hemihepatic vascular occlusion during resection of the liver. Surg Gynecol Obstet 1987; 164: 155-8. 